\title{
Normal pregnancy and delivery in a woman with severe underlying lung disease
}

\author{
ST WEISS, SE WEINBERGER, JW WEISS, TS JOHNSON
} From the Pulmonary Unit, Department of Medicine and Thorndike Memorial Laboratory, Beth Israel
Hospital and Harvard Medical School, Boston, Massachusetts, USA

Little information is available about the impact of pulmonary insufficiency on the course and outcome of a normal pregnancy, since severe lung disease with functional impairment is unusual in women during childbearing years. ${ }^{1-5}$ We report here a patient with pulmonary insufficiency of combined restrictive and obstructive type who delivered a normal baby after a closely monitored but relatively uneventful pregnancy.

\section{Case report}

A 27-year-old gravida 5, para 4 white woman was admitted to the hospital for pulmonary evaluation at 24 weeks of gestation. Her current problem had its onset three years before admission, when she was in hospital for 12 months with alcoholic hepatitis and acute pancreatitis. Complications included pancreatic abscesses with entero-cutaneous fistulae, a pancreatic pseudocyst, and severe adult respiratory distress syndrome. After numerous surgical procedures, she required mechanical ventilation for over six months; a tracheostomy was performed and recurrent pneumothoraces required tube drainage on several occasions.

One year before admission she was investigated for dyspnoea. The chest film showed diffuse bilateral reticulonodular shadowing. Arterial blood gases on room air were $\mathrm{Po}_{2} 60 \mathrm{mmHg}, \mathrm{PCO}_{2} 39 \mathrm{mmHg}$, and pH 7.45. Pulmonary function testing (table) showed combined obstructive and restrictive disease. A transbronchial

Address for reprint requests: Dr ST Weiss, Pulmonary Unit, Department of Medicine, Beth Israel Hospital, Boston, Massachusetts, USA. biopsy demonstrated only interstitial fibrosis. A trial of $\dot{\infty}$ steroids was attempted, but the patient did not return $\infty$ for follow-up, and the steroids were discontinued.

Her four previous pregnancies, the last at age 21 years, had been uncomplicated and not associated with any lung disease. She had smoked three packs of cigarettes per day since age 9 years. She was not taking any medication at the time of her hospital admission.

Her respiratory rate was 22 . Chest examination showed normal resonance to percussion, bilateral basal crackles, and a prolonged expiratory phase without wheezing. There was no evidence of pulmonary hypertension.

Results of pulmonary function tests are shown in the table. A flow-volume loop showed no evidence of fixed extrathoracic obstruction. Arterial blood gases on room air revealed a $\mathrm{PO}_{2}$ of $69 \mathrm{mmHg}$ with a $\mathrm{PCO}_{2}$ of $37 \mathrm{mmHg}$, and a pH of 7.45. Chest radiograph revealed small lungs and a diffuse reticulonodular interstitial infiltrate.

At 30 weeks gestation she developed a lower respiratory infection with fever and increased dyspnoea and tachypnoea.She improved on antibiotics, bronchodilators, chest physical therapy, and low flow oxygen. She remained in hospital for the duration of her pregnancy to prevent her from smoking heavily, to give her controlled oxygen, and to monitor her respiratory insufficiency. At 36.5 weeks she went into labour spontaneously and subsequently delivered a 4 pound 3 ounce girl without difficulty after a four hour labour. The baby had an Apgar score of 8 at one minute and 9 at five minutes.

\section{Discussion}

No standards are currently available in the literature to

Table Pulmonary function tests before, during, and immediately after pregnancy

\begin{tabular}{|c|c|c|c|c|c|c|c|}
\hline & $\begin{array}{l}\text { One year before } \\
\text { pregnancy }\end{array}$ & 26 weeks & 30 weeks & 33 weeks & 35 weeks & $\begin{array}{l}4 \text { days } \\
\text { postpartum }\end{array}$ & $\begin{array}{l}2 \text { weeks } \\
\text { postpartum }\end{array}$ \\
\hline $\begin{array}{l}\text { TLC (1) } \\
\text { RV (I) } \\
\text { RV/TLC \% } \\
\text { VC (I) } \\
\text { FEV }(1) \\
\text { DLCOSB }^{\text {I }}\end{array}$ & $\begin{array}{l}2.91(58 \%) \\
1.68(123 \%) \\
215 \% \\
1.28(35 \%) \\
0.96(33 \%) \\
8.4(50 \%)^{*}\end{array}$ & $\begin{array}{l}3.29(66 \%) \\
1.89(138 \%) \\
238 \% \\
1.40(39 \%) \\
0.85(29 \%) \\
4.9(28 \%)\end{array}$ & $\begin{array}{l}3 \cdot 20(64 \%) \\
1 \cdot 86(136 \%) \\
215 \% \\
1 \cdot 34(37 \%) \\
0.98(34 \%) \\
3.8(21 \%)\end{array}$ & $\begin{array}{l}3.39(68 \%) \\
1.60(117 \%) \\
175 \% \\
1 \cdot 79(49 \%) \\
1.16(40 \%) \\
4 \cdot 0(20 \%)\end{array}$ & $\begin{array}{l}3.38(68 \%) \\
1.72(124 \%) \\
188 \% \\
1.66(46 \%) \\
1.13(39 \%) \\
+\end{array}$ & $\begin{array}{l}2.95(59 \%) \\
1.49(107 \%) \\
185 \% \\
1.48(41 \%) \\
1.04(36 \%) \\
1.3(6 \%)\end{array}$ & $\begin{array}{l}3 \cdot 31(66 \%) \\
2 \cdot 24(164 \%) \\
252 \% \\
1 \cdot 15(32 \%) \\
0 \cdot 82(28 \%) \\
4 \cdot 3(22 \%)\end{array}$ \\
\hline
\end{tabular}

$\left(\mathrm{ml} \mathrm{min}^{-1} \mathrm{mmHg}^{-1}\right.$ )

*This value is a steady state diffusing capacity: all others are single breath values, corrected for haemoglobin.

+ The diffusion capacity was not performed on this date. 
help the physician in assessing whether a patient with respiratory insufficiency will be able to withstand the increased ventilatory requirements of pregnancy. Under normal circumstances, women without lung disease tolerate the $20 \%$ increase in oxygen consumption and the $45-50 \%$ increase in minute ventilation at term without any difficulty. The dyspnoea that is seen with normal pregnancies does not appear by be caused by limited respiratory reserve, but rather by an excessive minute ventilation for oxygen consumption, induced by high levels of progesterone during pregnancy.

However, in the patient with either obstructive or restrictive lung disease, one might expect the added ventilatory demands to impose a load that could not be tolerated by the pregnant woman. Gaensler and associates studied the course of patients with pulmonary insufficiency during pregnancy, and found that the increased demands of pregnancy were well tolerated by the mother. ${ }^{6}$ Although the patients did well during their pregnancy, it was observed that they did not experience as much hyperventilation as did their pregnant counterparts without lung disease. In addition, the women with pulmonary insufficiency generally met the increased ventilatory demands of pregnancy by an increased respiratory rate rather than the more commonly observed increase in tidal volume. Interestingly, patients with respiratory insufficiency did not experience worsening dyspnoea during their pregnancy, even though normal women frequently experience this symptom at some point during pregnancy.

Probably the most severe functional impairment has been reported in women with cystic fibrosis who have become pregnant. Approximately half of these patients experienced further decompensation during and after pregnancy, while the other half did not appear to have any significant deterioration. Of 13 infants born to mothers with cystic fibrosis, 11 were normal at birth although three were born prematurely. ${ }^{2}$ It has been suggested that a minimal vital capacity of one litre is necessary to sustain the ventilatory requirements of pregnancy, although a patient with severe kyphoscoliosis and a vital capacity of $800 \mathrm{ml}$ has been reported. ${ }^{7}$ In the latter case, the patient maintained a normal $\mathrm{Po}_{2}$, and the patient delivered a healthy infant with an Apgar score of 9 at one minute. In contrast, a patient with paralytic poliomyelitis and a vital capacity of approximately $670 \mathrm{ml}$ has been reported, whose pregnancy was complicated by severe dyspnoea, congestive heart failure, and the need for ventilatory support with a negative pressure ventilator. ${ }^{8}$

In our patient, there was actually a slight improvement in vital capacity during the course of pregnancy (table). This improvement may have been the result of her receiving intensive medical therapy in the hospital at that time. However, she did continue to smoke throughout her pregnancy, and the baby's low birth weight may reflect this or her underlying lung disease.

Gaensler and associates have suggested that a diseased respiratory system is more capable of handling the additional ventilatory requirements of pregnancy than the impaired heart can meet the increased circulatory needs. The relatively uneventful course of this patient's pregnancy, despite the presence of severe functional impairment from restrictive and obstructive disease, supports this viewpoint. However, intercurrent respiratory tract infections, such as occurred during this patient's pregnancy, pose a significant risk, and can precipitate worsening respiratory failure. Considering the more tenuous status of such a patient, it is important to maintain close observation throughout pregnancy and delivery in order to provide supportive therapy as early as possible, particularly supplemental oxygen to maintain adequate oxygen transport to the fetus. Cessation of cigarette smoking is also exceedingly important, as premature delivery, spontaneous abortion, low birth weight, and pregnancy complications are all increased in cigarette smokers. ${ }^{9}$

\section{References}

${ }^{1}$ Siegel B, Siegel S. Pregnancy and delivery in a patient with cystic fibrosis of the pancreas: report of a case. Obstet Gynecol 1960;16:438-40.

${ }^{2}$ Grand RJ, Talamo RC, di Sant'Agnese PA, Schwartz RH. Pregnancy in cystic fibrosis of the pancreas. JAMA 1966; 195:993-1000.

${ }^{3}$ Novy MJ, Tyler JM, Schwachman H, Easterday CL, Reid DE. Cystic fibrosis and pregnancy: report of a case, with a study of pulmonary function and arterial blood gases. Obstet Gynecol 1976;30:530-6.

${ }^{4}$ Plotz EJ, Patterson PR, Streit JH. Pregnancy in a patient with cystic fibrosis (mucoviscidosis) and diabetes mellitus. Am J Obstet Gynecol 1967;98:1105-10.

${ }^{5}$ Larsen JR Jr. Cystic fibrosis and pregnancy. Obstet Gynecol 1972;39:880-3.

${ }^{6}$ Gaensler EA, Patton WE, Verstraeten JM, Badger TL. Pulmonary function in pregnancy. III. Serial observations in patients with pulmonary insufficiency. Am Rev Tuberc 1953;67:779-97.

${ }^{7}$ Hung ET, Pelosi M, Langer A, Harrigan JT. Blood gas measurements in the kyphoscoliotic gravida and her fetus: report of a case. Am J Obstet Gynecol 1975;121 : 287-8.

${ }^{8}$ Woollam CHM, Houlton MCC. Respiratory failure in pregnancy. Anaesthesia 1976;31:1217-26.

${ }^{9}$ Smoking and Health: a report of the Surgeon General. Washington, DC: Government Printing Office. 1979. (DHEW publication no 79-50066.) 